\title{
Design and analysis of helium Brayton power cycles for HiPER reactor
}

\author{
Consuelo Sánchez ， Rafael Juárez ，Javier Sanz , Manuel Perlado
}

\section{H I G H L I G H T S}

- A helium Brayton cycle has been designed integrating the two energy sources of HiPER.

- The Brayton cycle has intercooling stages and a recovery process.

- The low temperature of HiPER heat sources results in low cycle efficiency (35.2\%).

- Two inter-cooling stages and a reheating process increases efficiency to over $37 \%$.

- Helium Brayton cycles are to be considered as candidates for HiPER power cycles.

\begin{abstract}
A B S T R A C T
Helium Brayton cycles have been studied as power cycles for both fission and fusion reactors obtaining high thermal efficiency. This paper studies several technological schemes of helium Brayton cycles applied for the HiPER reactor proposal. Since HiPER integrates technologies available at short term, its working conditions results in a very low maximum temperature of the energy sources, something that limits the thermal performance of the cycle. The aim of this work is to analyze the potential of the helium Brayton cycles as power cycles for HiPER. Several helium Brayton cycle configurations have been investigated with the purpose of raising the cycle thermal efficiency under the working conditions of HiPER. The effects of inter-cooling and reheating have specifically been studied. Sensitivity analyses of the key cycle parameters and component performances on the maximum thermal efficiency have also been carried out. The addition of several inter-cooling stages in a helium Brayton cycle has allowed obtaining a maximum thermal efficiency of over $36 \%$, and the inclusion of a reheating process may also yield an added increase of nearly 1 percentage point to reach $37 \%$. These results confirm that helium Brayton cycles are to be considered among the power cycle candidates for HiPER.
\end{abstract}

\section{Introduction}

Helium Brayton cycles are promising candidates for the power conversion in future fission (Generation IV: HTGRs and SFR) [1-5] and fusion reactors [6-9]. Results show high thermal efficiencies, higher than those obtained with the Rankine cycle of current nuclear plants.

HiPER (high power laser energy research) is the ESFRI-EU project aimed to demonstrate the feasibility to produce electric power by direct-drive inertial confinement fusion [10]. HiPER is being developed integrating technologies available at short term to minimize risks. For the HiPER reactor proposal, the option of a self cooled lead lithium (SCLL) blanket was proposed [11] and two different arrangements of the first wall (FW) cooling were set out: integrated first wall-blanket (IFWB) and separated first wall-blanket (SFWB). In IFWB configuration all the fusion energy of the reactor is extracted with a single coolant ( $\mathrm{LiPb}$ ) whereas in SFWB there are two different coolants, one cooling the FW $(\mathrm{He})$ by removing $22 \%$ of the total energy and the other cooling the blanket (LiPb) removing the remaining $78 \%$. In a previous work [12], a simple and ideal helium Brayton power cycle was analyzed for both IFWB and SFWB options in order to compare them in terms of power cycle. SFWB yielded a higher thermal efficiency than IFWB.

This paper studies several helium Brayton cycle configurations for the SFWB arrangement with the purpose of raising the thermal efficiency of the power cycle. In most of the studies referenced at the beginning of this introduction, the helium cycle operates at a maximum temperature above $680^{\circ} \mathrm{C}$, while in HiPER reactor it does not exceed $480^{\circ} \mathrm{C}$, which is quite restrictive from a thermodynamic viewpoint. So, this paper analyzes the possibilities of helium Brayton cycles as candidate to HiPER power cycles. The effects of the inter-cooling and reheating processes are specially analyzed 
Table 1

Energy source data of SCLL.

\begin{tabular}{lll}
\hline & FW & Blanket \\
\hline Fluid & He & LiPb \\
Inlet temperature $\left({ }^{\circ} \mathrm{C}\right)$ & $>350.0$ & 350.0 \\
Outlet temperature $\left({ }^{\circ} \mathrm{C}\right)$ & 650.0 & 450.0 \\
Thermal power $(\mathrm{MWth})$ & 375.0 & 1327.5 \\
\hline
\end{tabular}

over the cycle optimum performance. Finally sensitivity analyses are included to quantify the effect of key cycle parameters and component performances on the maximum thermal efficiency.

\section{Helium Brayton power cycle}

The SFWB configuration for HiPER reactor implies the availability of two different energy sources: the blanket coolant is LiPb whereas the FW coolant is helium. Table 1 lists their thermal data. The temperatures of the two coolants are set by the structural materials. EUROFER97 is proposed for the blanket, and EUROFER97-ODS is proposed for the FW. The most critical issues for EUROFER97 are irradiation induced hardening and shift of ductile-brittle transition temperature (DBTT) after irradiation at temperatures below about $350^{\circ} \mathrm{C}$. The DBTT in unirradiated EUROFER is around $-90^{\circ} \mathrm{C}$, but when irradiated at $300^{\circ} \mathrm{C}$ to $8 \mathrm{dpa}$ increases to $40^{\circ} \mathrm{C}$ [13]. Maintaining the inlet temperatures of both coolants above $350^{\circ} \mathrm{C}$, these behaviors are mitigated, being this figure a value probably conservative. The low outlet temperature for $\mathrm{LiPb}$ is due to the corrosive behavior of the LiPb, while for helium, the upper limit corresponds to the maximum temperature the steel can withstand $\left(650^{\circ} \mathrm{C}\right.$ [13]). As a result of all these, the temperature range for the $\mathrm{LiPb}$ coolant is both narrow and low, imposing very stringent boundary conditions to the power cycle.

In all configurations studied in this work, the two energy sources are integrated into the power cycle, consequently, all the thermal power output of the reactor is being used. As the same fluid ( $\mathrm{He}$ ) is used in the power cycle and the FW cooling, the arrangement of the two energy sources is shown in Fig. 1. In the heat exchanger (HEx), the LiPb yields its energy to the helium flowing in the power cycle. Then, the helium flow is divided into two flows, so one of them corresponds with the necessary fraction for cooling the FW achieving its upper temperature (Table 1). The remaining helium flow bypasses the reactor and it is mixed with the first one raising the maximum temperature of the power cycle.

The power cycle scheme represented in Fig. 1 is the first under study. It corresponds to an indirect/direct cycle, with one intercooling stage (Ic) and a recuperation process $(\mathrm{Rc})$, both contributing to improve the cycle thermal efficiency. A two-shaft arrangement is

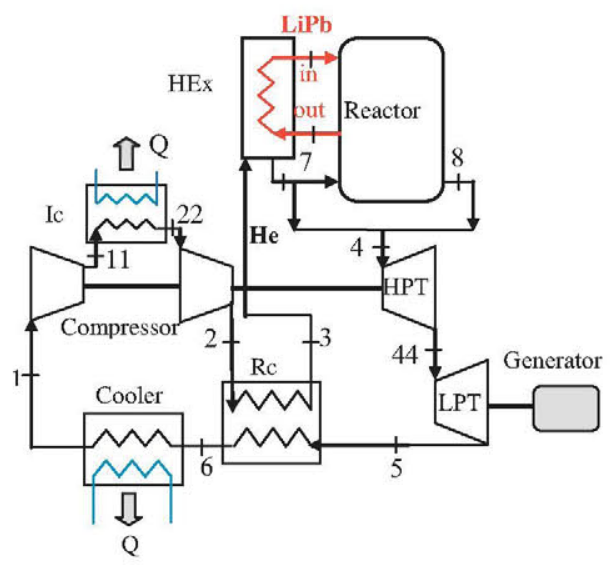

Fig. 1. Helium Brayton power cycle for the SFWB layout. proposed where the high pressure (HP) turbine (T) drives the compressor (C) and the low pressure (LP) turbine drives the generator. With this arrangement, the LP turbine and the generator turn at synchronous speed (3000 rpm) or submultiples of that speed and a higher one is possible for the HP turbine and the compressor thus allowing better compressor performance. Multiple shaft designs are more expensive but provide greater flexibility in the operation of the facility.

\subsection{Model description}

The cycle power is modeled based on the energy balances and on the efficiency equations of the individual components. The assumed hypotheses and input data are listed below:

- Pressure drops in the heat exchangers are considered:

o Intercoolers: $\Delta P_{\mathrm{lc}}=P_{11}-P_{22}=0.05 \times 10^{3} \mathrm{kPa}$ [14]

- Recuperator: $\Delta P_{\mathrm{HP}}=P_{2}-P_{3}=0.05 \times 10^{3} \mathrm{kPa} ; \Delta P_{\mathrm{LP}}=P_{5}-P_{6}=$ $0.08 \times 10^{3} \mathrm{kPa}[4]$

- LiPb heat exchanger: $\Delta P_{\mathrm{Hex}}=P_{3}-P_{7}=0.04 \times 10^{3} \mathrm{kPa}[9]$

- Cooler (Co): $\Delta P_{C_{0}}=P_{6}-P_{1}=0.032 \times 10^{3} \mathrm{kPa}[14]$

- Pressure drops in pipelines, in junctions and in flow splitting are not considering.

- Turbines and compressors are considered adiabatic with polytropic efficiencies $\left(\eta_{\mathrm{P}}\right)$ of $93 \%$ and $90 \%$ respectively [2].

- Recuperator effectiveness $\left(\varepsilon_{\mathrm{RC}}\right)$ is 0.95 , heat exchanger effectiveness $\left(\varepsilon_{\mathrm{HEx}}\right)$ is 0.95 [2].

- Identical inlet temperature for the compressors: $T_{1}=T_{i, \text { in }}=303 \mathrm{~K}$ $\left(30^{\circ} \mathrm{C}\right)[1]$.

- Total compressor pressure ratio $\left(r_{\mathrm{c}}\right): r_{\mathrm{c}}=\left(P_{2} / P_{1}\right)$ $\left(1.2 \leq r_{\mathrm{c}}=P_{2} / P_{1} \leq 3.5\right)$.

- Identical pressure ratio $\left(r_{\mathrm{ci}}\right)$ for the compressors: $r_{\mathrm{ci}}=$ $\left(p_{i_{\text {out }}} / p_{i_{\text {in }}}\right)=\sqrt[N]{r_{\mathrm{c}} / \sum_{j}\left(1-\Delta P_{\text {Icj }}\right)}$ [15] (where $N$ is the number of compressors; $i_{\text {in }}, i_{\text {out }}$ are the inlet and outlet of the $i$-th compressor; and $j$ is the index for the intercoolers).

- Maximum pressure: $P_{2}=8000 \mathrm{kPa}$ [9].

- The kinetic and potential energy changes are neglected in all components.

- Helium is considered as an ideal gas.

- The thermodynamic properties of the LiPb are obtained from Karditas et al. [16].

Cycle performance is modeled in steady state and the working conditions for each cycle component are calculated using the Engineering Equation Solver (EES) [17].

\subsection{Results}

The power cycle performance is calculated as a function of the compression ratio $\left(r_{\mathrm{c}}\right)$ in order to find the value that maximizes the cycle thermal efficiency for the thermal power distribution listed in Table 1 . The optimum compression ratio $\left(r_{\mathrm{c}}\right)$ happens to be 1.8 with a maximum efficiency of $35.3 \%$. Table 2 shows the main results for maximum thermal efficiency. The recuperator outlet temperature in the cold side depends on $r_{\mathrm{c}}$, being $324^{\circ} \mathrm{C}$ with $r_{\mathrm{C}}=1.8$, lower than $350^{\circ} \mathrm{C}\left(T_{\text {in }}(\mathrm{LiPb})\right)$. The reactor inlet temperature of helium is greater than $350^{\circ} \mathrm{C}$ over full range of $r_{\mathrm{c}}$ considered. Therefore, the results for maximum efficiency satisfy the boundary conditions imposed by de energy sources.

The optimal compression ratio is low, which is advantageous for the design of the helium compressors and turbines. Because of the high specific heat and the low density of helium, helium compressors and turbines are long, with a large number of stages and short blades that leads to high losses in each stage. As the optimal compression ratio is low, the turbomachinery will be shorter and 
Table 2

Results for maximum thermal efficiency.

\begin{tabular}{ll}
\hline$\eta_{\mathrm{th}}(\%)=35.32$ & $P_{\text {net }}(\mathrm{MW})=601.32$ \\
$\dot{m}_{\mathrm{Brayton}}(\mathrm{kg} / \mathrm{s})=2136.0$ & $\dot{m}_{\text {Reactor }}(\mathrm{kg} / \mathrm{s})=350.1$ \\
Compressor & \\
$P_{\mathrm{C} 1}(\mathrm{kPa})=4431.0, r_{\mathrm{C} 1}=1.35, W_{\mathrm{C} 1}(\mathrm{MW})=477.4$ & \\
$P_{\mathrm{C} 22}(\mathrm{kPa})=5939.0, r_{\mathrm{C} 2}=1.35, W_{\mathrm{C} 2}(\mathrm{MW})=477.4$ & \\
Recuperator & \\
High pressure: $T_{2}\left({ }^{\circ} \mathrm{C}\right)=73.0, T_{3}\left({ }^{\circ} \mathrm{C}\right)=324.0$ \\
LoW pressure: $T_{5}\left({ }^{\circ} \mathrm{C}\right)=337.3, T_{6}\left({ }^{\circ} \mathrm{C}\right)=86.2$ \\
IHEx \\
$T_{7}\left({ }^{\circ} \mathrm{C}\right)=443.7$ \\
Turbine \\
$P_{\mathrm{T} 4}(\mathrm{kPa})=7910.0, T_{\mathrm{T} 4}\left({ }^{\circ} \mathrm{C}\right)=477.5, r_{\mathrm{THP}}=1.39$ \\
$P_{\mathrm{T} 44}(\mathrm{kPa})=5707.0, T_{\mathrm{T} 44}\left({ }^{\circ} \mathrm{C}\right)=391.5, r_{\mathrm{TLP}}=1.26$ \\
$W_{\mathrm{THP}}(\mathrm{MW})=954.6, W_{\mathrm{TLP}}(\mathrm{MW})=601.32$ \\
\hline
\end{tabular}

the helium mass flow rate higher, which result in a better turbomachinery design that will help to improve the cycle efficiency. It should be also noted that the evolution of efficiency as a function of the compressor pressure ratio is fairly flat in the vicinity of the optimum $r_{\mathrm{c}}\left(1.62<r_{\mathrm{c}}<2.0\right)$, so that the thermal efficiency will be maintained near at its maximum value $\left(\eta_{\mathrm{th}} \geq 35 \%\right)$ even if the $r_{\mathrm{C}}$ would be modified for component design issues or for structural materials.

\section{Inter-cooling process}

The main effect of inter-cooling process is the reduction of the power consumed by the compressor, which increases the thermal efficiency of the cycle even though the pressure loss of each intercooler makes necessary to increase in the compression ratio for each compressor to maintain the same overall compression ratio in the system.

Fig. 2 shows the cycle efficiency as a function of the compressor pressure ratio for a few numbers of inter-cooling stages. It can be seen that as more inter-cooling stages are added the higher the thermal efficiency. However, the benefit diminishes with each new addition, being the increment very important with the first stage, while the third one brings just a meager $15 \%$ of that. It is also observed that the maximum efficiency moves toward higher compression ratios with more stages, although always remaining low $\left(r_{\text {copt }}<2\right)$. On the other hand, adding inter-cooling stages increases the complexity of the installation and makes it more expensive, so the decision of the appropriate number of inter-cooling stages requires a comprehensive cost analysis to maximize the economic profitability (return of investment). This analysis is beyond the scope of this paper so the authors have selected a nominal cycle

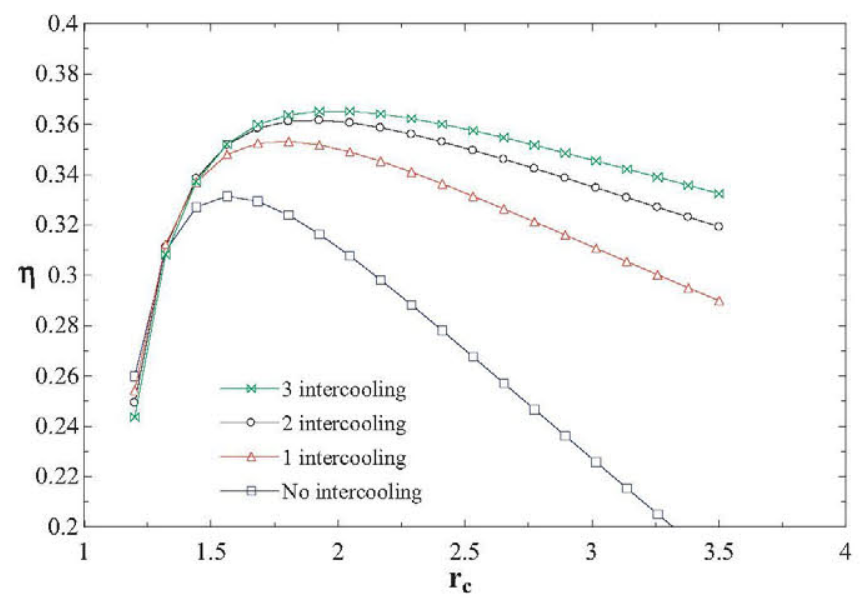

Fig. 2. Effect of inter-cooling stages on the cycle efficiency.

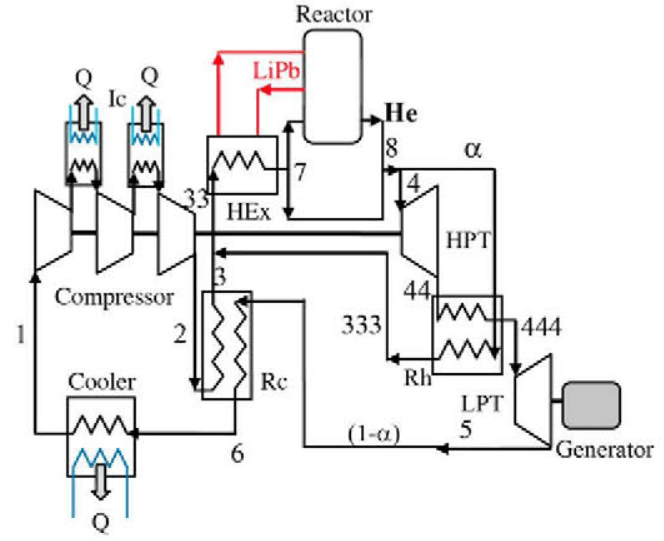

Fig. 3. Layout of helium Brayton power cycle with reheating.

with two stages for the remaining analyses included in this work. This configuration shows an optimum compression ratio of 1.93 , a maximum thermal efficiency of $36.2 \%$ and a power output of 615.6 MW.

\section{Reheating process}

The reheating process consists in helium heating process, partially expanded in the HP turbine, to raise its temperature as much as possible before it completes its expansion in the LP turbine. The effect of this reheating is the rise of the turbine specific work. However, this does not necessarily lead to a higher thermal efficiency of the cycle and depending on the proposed scheme and the working conditions, the efficiency may or may not increase in relation to the cycle without reheating.

The layout studied in this paper is that depicted in Fig. 3. This scheme is similar to those used in current nuclear plants. The reheating uses a fraction of the hot helium mass $(\alpha)$ to heat the rest of the helium $(1-\alpha)$ that has been expended in the HP turbine. This takes place in the heat exchanger called reheater (Rh) located between the HP and the LP turbine sections.

The reheating process is characterized by two parameters: the terminal temperature difference on the hot side (TTD $\left.=T_{4}-T_{444}\right)$, and the hot helium mass fraction $(\alpha)$. The range of the pressure ratio where the installation is feasible is determined for different values of the parameters above defined (feasible means that the boundary conditions imposed by the energy sources are met). But the $r_{\mathrm{c}}$ range of interest is that where the thermal efficiency is larger with reheating than without it. The hypotheses and input data are the same as those of Section 2. Additionally, the pressure drops in the reheater are considered identical to those in the recuperator (see Section 2.1). Table 3 shows the results of this analysis, including also the optimum compression ratio and the maximum thermal efficiency for each set of parameters defined in the mentioned table. Fig. 4 displays the maximum thermal efficiency as a function of the helium mass fraction for TTD equal to 20 and to $50^{\circ} \mathrm{C}$.

It is observed that for each TTD there is a minimum value for $\alpha$, and for each value of $\alpha$ there is a specific range of compression ratios that make the installation is feasible. Furthermore, it is found that the $\mathrm{r}_{\mathrm{C}}$ range is in all cases smaller than that of the cycle without reheating. For each value of TTD, the thermal efficiency of the reheat cycle is larger than the one achievable without reheating only in a certain range of $\alpha$ and for a specific range of $r_{c}$, smaller than the feasible working range. Fig. 4 proves that, from $\mathrm{TTD} \leq 50^{\circ} \mathrm{C}$, there is an optimum value of the mass fraction which gives the maximum efficiency. Its optimum compression ratio is greater than the one for a no-reheating cycle. It is found that the optimum mass fraction increases with decreasing TTD. In 
Table 3

Maximum thermal efficiency and $r_{\mathrm{c}}$ optimum for several values of the parameters TTD and $\alpha$.

\begin{tabular}{|c|c|c|c|c|c|c|c|c|c|c|c|c|}
\hline \multirow{2}{*}{$\begin{array}{l}\text { TTD } \\
\alpha(\%)\end{array}$} & \multicolumn{3}{|l|}{$50^{\circ} \mathrm{C}$} & \multicolumn{3}{|l|}{$30^{\circ} \mathrm{C}$} & \multicolumn{3}{|l|}{$20^{\circ} \mathrm{C}$} & \multicolumn{3}{|c|}{ Without reheating } \\
\hline & $r_{c}$ & $\eta_{\max }(\%)$ & $r_{\text {copt }}$ & $r_{c}$ & $\eta_{\max }(\%)$ & $r_{\text {copt }}$ & $r_{c}$ & $\eta_{\max }(\%)$ & $r_{\text {copt }}$ & $r_{c}$ & $\eta_{\max }(\%)$ & $r_{\text {copt }}$ \\
\hline 10 & $1.68-1.93$ & 36.25 & 1.93 & 1.684 & 35.70 & 1.69 & - & - & - & & & \\
\hline 15 & $1.80-2.41$ & 36.44 & 2.29 & $1.80-2.05$ & 36.85 & 2.05 & $1.80-1.93$ & 36.87 & 1.93 & & & \\
\hline 20 & $1.80-3.02$ & 36.29 & 2.29 & $1.80-2.65$ & 36.82 & 2.29 & $1.80-2.42$ & 37.08 & 2.29 & $1.68-3.5$ & 36.16 & 1.93 \\
\hline 25 & $1.93-3.50$ & 36.15 & 2.17 & $1.93-3.38$ & 36.67 & 2.29 & $1.93-3.14$ & 36.93 & 2.29 & & & \\
\hline 35 & $2.17-3.50$ & 35.88 & 2.17 & $2.17-3.50$ & 36.40 & 2.17 & $2.17-3.50$ & 36.65 & 2.17 & & & \\
\hline 45 & $2.53-3.50$ & 35.30 & 2.53 & $2.53-3.50$ & 35.84 & 2.53 & $2.53-3.50$ & 36.10 & 2.53 & & & \\
\hline
\end{tabular}

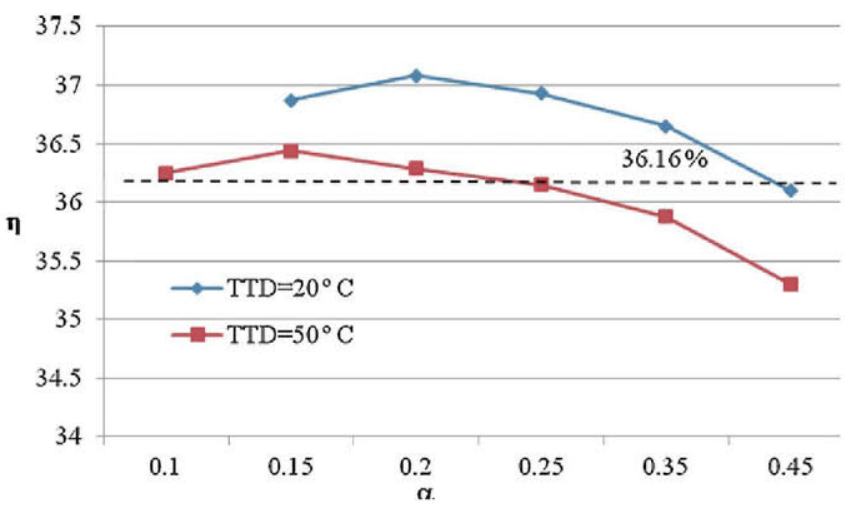

Fig. 4. Effect of $\alpha$ and TTD on the maximum cycle efficiency.

view of the results obtained with the values used for the reheating parameters in this work, the largest efficiency (37.1\%) has been archived with TTD $=20^{\circ} \mathrm{C}, \alpha=20 \%$ and $r_{\mathrm{c}}=2.3$. Therefore, the reheating process is to be included and then the cycle performance maximized as a function of the defined parameters.

\section{Sensitivity analysis}

The influence of the key cycle parameters on the maximum efficiency thermal and on the optimum compression ratio is studied. The studied parameters are: maximum temperature and pressure of the cycle, cycle minimum temperature, turbine polytropic efficiency, compressor polytropic efficiency, heat exchanger effectiveness and recuperator effectiveness. The purpose of this study is to determine the relative importance of each parameter with respect to the maximum efficiency. The studies are based on the configuration of two inter-cooling stages and when a parameter is studied the other parameters are fixed to their baseline values (i.e. $T_{\text {out }}(\mathrm{LiPb})=450^{\circ} \mathrm{C}, P_{\max }=8 \mathrm{MPa}, T_{\min }=T(\mathrm{Comp})=30^{\circ} \mathrm{C}, \eta_{\mathrm{PT}}=93 \%$, $\left.\eta_{\mathrm{PC}}=90 \%, \varepsilon_{\mathrm{HEx}}=0.95, \varepsilon_{\mathrm{Rc}}=0.95\right)$.

Fig. 5 shows the influence of all the analyzed parameters on the maximum thermal efficiency of the cycle. Table 4 gives the efficiency increments for reasonable improvements in the discussed parameters.

From all the cycle parameters analyzed, it is worth highlighting the influence of the maximum temperature cycle (turbine inlet

Table 4

Cycle efficiency sensitivity to cycle parameters.

\begin{tabular}{lll}
\hline Parameters & $\begin{array}{l}\text { Change over } \\
\text { reference value }\end{array}$ & $\begin{array}{l}\text { Change in } \eta \\
\text { (\%-points) }\end{array}$ \\
\hline Temperature out LiPb & $+50^{\circ} \mathrm{C}$ & +3.4 \\
Temperature in compressor & $-5{ }^{\circ} \mathrm{C}$ & +0.8 \\
Maximum pressure & $+2 \times 10^{3} \mathrm{kPa}$ & +0.7 \\
HEx effectiveness & $+1 \%$ & +0.1 \\
Recuperator effectiveness & $+2 \%$ & +1.3 \\
Turbine efficiency & $+2 \%$ & +1.0 \\
Compressor efficiency & $+2 \%$ & +1.1 \\
\hline
\end{tabular}

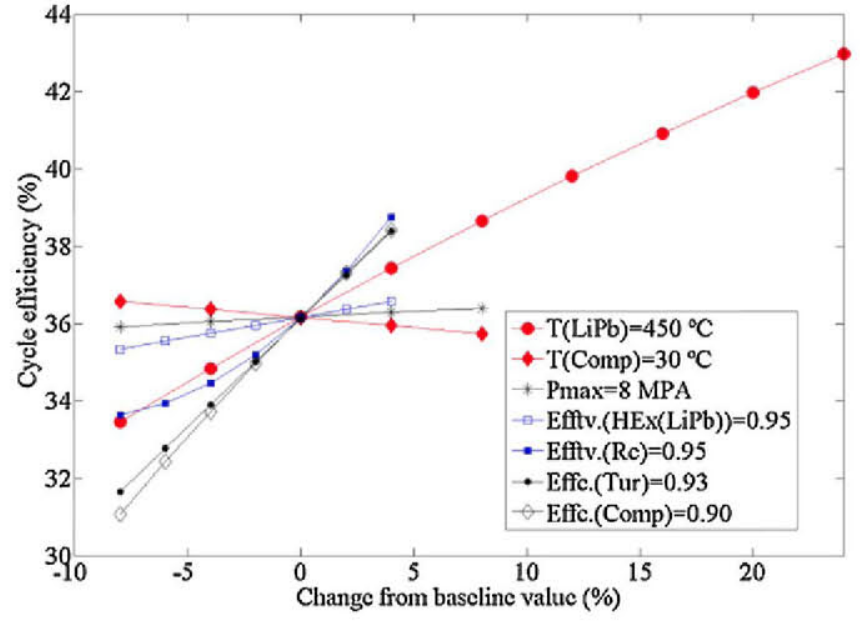

Fig. 5. Sensitivity of the cycle efficiency to cycle parameters.

temperature). This temperature is determined by the LiPb reactor outlet temperature. For a $100^{\circ} \mathrm{C}$ increase in the $\mathrm{LiPb}$ temperature, the maximum efficiency rises from 36.2 to $42.5 \%$ hardly varying the optimum $r_{c}$ from 1.93 to 2.05. Nowadays, using EUROFER as structural material, the outlet temperature must be $450^{\circ} \mathrm{C}$ as mentioned earlier. However, in the near future, the use of promising Al-coatings may rise the outlet temperature up to $550^{\circ} \mathrm{C}$, thus allowing the cycle thermal efficiency boost to $42 \%$.

From the side of the components, it is worth highlighting the recuperator. A 2 percentage point increase in the effectiveness of this element would yield a cycle efficiency increase of 1.2 percentage points, causing also a small drop in the optimum compression ratio. It has been found that the effect of improving the recuperator effectiveness is more important with low compression ratios, just around the optimum compression ratio. However, larger effectiveness means also a larger recuperator and therefore a more expensive equipment.

\section{Conclusions}

Several He Brayton cycle schemes to the SFWB layout for HiPER has been investigated in order to maximize the thermal efficiency and to know what values can be achieved considering that the maximum temperature of the power cycle does not exceed $480^{\circ} \mathrm{C}$. A two-shaft helium Brayton cycle with one inter-cooling stage and a recovery process has been studied first. The maximum thermal efficiency of the cycle has turned out to be $35.3 \%$ with an optimum compression ratio of 1.8. Based on this layout, the effect of including additional inter-cooling stages over the maximum thermal efficiency has been analyzed. The results suggest that the original configuration must be modified to include at least two inter-cooling stages because the higher maximum efficiency, 36.2\% (+0.9 percentage points) for two stages. However, the addition of more stages would require a detailed economic assessment. Based 
on the layout with two inter-cooling stages, a reheating process is included in a scheme similar to those of current nuclear power plants. From the results showed in this paper, it is concluded that a reheating process should be included because with adequate values for the parameters defining the reheating (TTD and $\alpha$ ) and the compressor ratio $\left(r_{\mathrm{c}}\right)$, the cycle efficiency will be increased, raising more than $37 \%$. Finally, it has been found that the cycle maximum temperature is the parameter that has the most relevant impact on the cycle thermal efficiency, having obtained that an increase of $100{ }^{\circ} \mathrm{C}$ would provide a cycle maximum efficiency of $42.5 \%$ ( +6.3 percentage points). These figures suggest that in the near future it will be possible to have a helium Brayton cycle with a thermal efficiency exceeding $40 \%$, and considering that helium is both chemically and radiologically inert, this put place these cycles among the candidates to become the HiPER power cycle.

\section{References}

[1] C. Wang, et al., Design of a power conversion system for an indirect cycle, helium cooled Pebble Bed Reactor system, in: Proceedings of 1st International Topical Meeting on HTR Technology, Netherlands, April 2002.

[2] X. Yan, et al., Cost and performance design approach for GTHTR300 power conversion system, Nuclear Engineering and Design 226 (2003) 351-373.

[3] H. Zhao, P.F. Peterson, Multiple reheat helium Brayton cycles for sodium cooled fast reactors, Nuclear Engineering and Design 238 (2008) 1535-1546.

[4] L.E. Herranz, et al., Power cycle assessment of nuclear high temperature gascooled reactors, Applied Thermal Engineering 29 (2009) 1759-1765.
[5] G.D. Pérez-Pichel, et al., Potential application of Rankine and He-Brayton cycles to sodium fast reactors, Nuclear Engineering and Design 241 (2011) 2643-2652.

[6] R. Schleicher, et al., An assessment of the Brayton cycle for high performance power plants, in: 14th ANS Topical Meeting on Fusion Energy, USA, October 2000.

[7] M.S. Tillack, et al., Fusion power core engineering for the ARIES-ST power plant, Fusion Engineering and Design 65 (2003) 215-261.

[8] S. Ishiyama, et al., Study of steam, helium and supercritical $\mathrm{CO}_{2}$ turbine power generations in prototype fusion power reactors, Progress in Nuclear Energy 50 (2008) 325-332.

[9] J.I. Linares, et al., Power conversion systems based on Brayton cycles for fusion reactors, Fusion Engineering and Design 86 (2011) 2735-2738.

[10] J.M. Perlado, et al., IFE plant technology: overview and contribution to HiPER proposal, in: Proceedings of SPIE, vol. 8080, 2011.

[11] R. Juárez, et al., Studies of a self cooled lead lithium blanket for HiPER reactor, in: Oral presentation in 7 th Inertial Fusion Science and Applications, IFSA Proceedings, 2011.

[12] C. Sánchez, Estudio del ciclo Brayton con Helio como ciclo de potencia para HiPER, UNED/DIE-IN-01CS, 2011.

[13] R. Lindau, et al., Present development status of EUROFER and ODS-EUROFER for application in blanket concepts, Fusion Engineering and Design 75-79 (2005) 989-996.

[14] R.L. Moore, Power conversion study for high temperature gas-cooled reactors, in: Proceedings of ICAPP, Korea, May 2005.

[15] V. Dostal, et al., A supercritical carbon dioxide cycle for next generation nuclear reactors, MIT-ANP-TR-100, 2004.

[16] P.J. Karditsas, M.-J. Baptise, Thermal and structural properties of fusion related materials, UKAEA FUS 294, June 1995. <http://www-ferp.ucsd.edu/LIB/PROPS/ PANOS/lipb.ht ml>.

[17] S.A. Klein, Engineering Equation Solver v8.745, F-Chart Software, Madison, WI, 2011. 